\title{
It's Raining Babies? Flooding and Fertility Choices in Bangladesh
}

\author{
Brian C. Thiede ${ }^{1, a}$, Joyce J. Chen ${ }^{2}$, Valerie Mueller ${ }^{3}$, Yuanyuan $\mathrm{Jia}^{2}$, \& Carolynne Hultquist ${ }^{1}$ \\ ${ }^{1}$ Pennsylvania State University ${ }^{2}$ The Ohio State University ${ }^{3}$ Arizona State University \\ ${ }^{a}$ Corresponding author: 111A Armsby Building, University Park, PA 16802; 814-865-2561; bct11@ psu.edu
}

April 9, 2020

\begin{abstract}
A growing demographic literature has examined the impacts of climatic variability on human populations. Most of this work has focused on migration, morbidity, and mortality. Much less attention has been given to the effects of climate change on fertility, which represents an important gap given many plausible reasons to expect such effects. We address this issue by examining the relationship between exposure to flooding and fertility in Bangladesh. We link birth records $(n=355,532$ person-years) from the Demographic and Health Survey (DHS) with satellite-derived measures of flooding from 2002 through 2014 and estimate statistical models of the relationship between flood exposure and subsequent fertility outcomes. We also conduct secondary analyses of the relationship between flood exposure and four expected causal pathways: women's marriage, contraceptive use, employment, and health. Results suggest that flood exposure reduces the probability of childbearing, and that this effect operates with a two-year lag. Negative effects are concentrated among women with a primary school education or higher and low-parity women. In contrast, women at high parities (e.g., at or above four) tend to increase their fertility in response to flooding. We find little evidence that observed flooding effects operate through the causal pathways we test, raising questions for future research about the mechanisms that explain our findings.
\end{abstract}

\section{Acknowledgements}

Thiede acknowledge assistance provided by the Population Research Institute at Penn State University, which is supported by an infrastructure grant from the Eunice Kennedy Shriver National Institute of Child Health and Human Development (P2CHD041025). Thiede also acknowledges support from USDA National Institute of Food and Agriculture and Multistate Research Project \#PEN04623 (Accession \#1013257). 


\section{Introduction}

A growing literature in demography documents the impacts of climatic variability on human population processes, and to date focuses largely on migration, morbidity, and mortality (Carleton \& Hsiang 2016; Deschênes \& Greenstone 2011; Fussell et al. 2014; Grace et al. 2015; McMichael et al. 2006). Less attention has been given to assessing potential climate-induced changes in fertility despite plausible reasons to expect climate impacts on reproductive outcomes (Grace 2017). ${ }^{1}$ Empirically evaluating the presence (or absence) of such impacts can provide new insights into the complex, multi-dimensional ways in which households respond to environmental change. Given the important consequences of fertility patterns for development outcomes at both the micro and macro levels (De Sherbinin et al. 2008; Eastwood \& Lipton 1999; Eloundou-Enyegue \& Williams 2006), this evidence can also improve understandings of the overall costs of climate change.

This paper contributes to the emerging literature on climate and fertility by examining the relationship between flooding and fertility in Bangladesh. Fluvial and coastal flooding routinely affect parts of the country, and such flooding is expected to increase in frequency and severity due to anthropogenic climate change (Auerbach et al. 2015; Bhuiyan \& Dutta 2012; Islam \& Uyeda 2007; Mizra 2011). Flood events have been linked to multiple adverse economic and demographic outcomes in prior research (Call et al. 2017; Chen et al. 2017; Gray \& Mueller 2012), but the impacts of flooding on fertility have not been studied in this context (or elsewhere). We do so here by linking birth records from four rounds of the Bangladesh Demographic and Health Survey (DHS) to high-resolution data on flooding from 2002 to 2014 and then estimating the relationship between local flood exposure and the probability of childbearing in subsequent years. We also

\footnotetext{
${ }^{1}$ For recent exceptions see Barreca et al. (2018), Eissler et al. (2019), Sellers \& Gray (2019), and Simon (2017).
} 
conduct secondary analyses of causal pathways that we expect to link flooding and fertility. Overall, our study of fertility responses to recent flooding allows us to consider the demographic consequences of plausible flooding patterns under future climate change scenarios.

The paper proceeds as follows. In the next section we outline the theoretical reasons to expect exposure to flooding to affect fertility rates. We then describe the data, key measures, and analytic methods used in this study. The next sections present our main results, robustness checks, and preliminary evidence of causal mechanisms. We conclude by discussing the broader implications of our findings and identifying objectives for future research in this emerging line of population-environment research.

\section{Environmental Change, Flooding, and Fertility}

Household responses to environmental change (and second-order impacts) may involve multiple behavioral changes and modifications to family structure. Demographers' attention to households' "multi-phasic" responses to economic and environmental stressors underlines the complexity of adaptation strategies (Bilsborrow 1987; Davis 1963; Kalipeni 1996), which may include both in and ex situ responses. These observations motivate our attention to the effects of climatic variability — and specifically, in this case, flooding — on fertility. The regulation of the timing and number of births represents an important means of controlling family size and structure. However, this outcome has been largely ignored in recent demographic research on climate change, which has instead focused largely on households' use of migration to adapt to climate shocks (Borderon et al. 2019; Fussell et al. 2014; Hunter et al. 2015).

Drawing on the broader fertility literature, we argue that such impacts should be expected and may operate through at least four broad sets of mechanisms. First, flood-induced morbidity 
and mortality may increase fertility by spurring replacement effects and reducing perceived survival probabilities among current and future children (Heuveline \& Poch, 2007; Nobles et al. 2015). That is, parents may seek to replace children killed in flooding (or the second-order consequences of flooding) or may have an additional child because they perceive heighted child mortality risk associated with flooding.

Second, the impacts of flooding may affect fertility via biological mechanisms. In particular, flooding may result in high levels of stress, changing food consumption, and related declines in health that may reduce fertility via changes in fecundity or the risk of conception (Bailey et al. 1992; Bongaarts 1980). Such changes may occur due to the direct impacts of flooding on food production (Douglas 2009) or because of broader disruptions that affect income, stress, and other dimensions of health (Banerjee 2007). Third, flooding may place upward pressure on fertility by disrupting access to contraceptives (Behrman \& Weitzman 2016; Sellers \& Gray 2019). Access may be disrupted due to barriers that prevent local clinics from being supplied or make it difficult for women to physically access suppliers. Women's economic access to contraceptives may also change due to flood-induced changes in income and/or savings.

Fourth, flooding may disrupt intra-household dynamics in ways that affect reproductive outcomes - although the direction of these effects may vary. For one, the economic consequences of flooding may disrupt local marriage markets, affecting the timing of marriage and the selection of partners (Mobarak et al. 2013). Additionally, flood-induced migration may reduce fertility by leading to the physical separation of spouses (Gray \& Mueller 2012). Negative income shocks may also increase the frequency of domestic violence and other forms of intra-household conflict, and otherwise lead to declines in emotional well-being and women's empowerment (Buller et al. 2018; Hidrobo et al. 2014). Further, the impacts of floods (e.g., making fields inaccessible, causing 
blackouts) may result in changing time allocation for leisure and labor among household members. Reduced opportunities for employment may put upward pressure on fertility by increasing leisure time among both spouses (Burlando 2014; Udry 1970) or increasing the demand for child labor, whether in the market or within the household. Conversely, flooding may have labor market effects—such as increased job-searching, incentivizing transitions from domestic to paid work among women - that reduce fertility.

Given the multiple pathways through which flooding can plausibly affect fertility, there is a strong basis to expect that floods and their second-order socioeconomic consequences will influence patterns of childbearing. However, the proposed pathways do not operate in the same direction and may have heterogeneous effects across sub-populations, leaving the net effect of flooding on fertility an empirical question. We address this issue in the case of Bangladesh, linking demographic records to satellite-based measures of flooding to estimate the effects of flood exposure on fertility, and to investigate the causal pathways described above.

\section{Research Objectives}

Our overall goal is to assess the effects of exposure to flooding on the probability of childbearing. We achieve this main goal by addressing three specific aims. First, we estimate the overall relationship between exposure to flooding and the probability of having one or more child in a given year across our entire sample. Second, we evaluate whether this effect varies across subpopulations that we expect to vary in terms of their vulnerability to flooding and ability or propensity to modify their fertility in response to flood exposures. Third, we conduct tests of plausible causal mechanisms by estimating the association between flood exposure and women's marital status, contraceptive use, employment, and body mass index (BMI). 


\section{Analytic Strategy}

\section{Data and Measures}

To address these aims, we combine demographic records from the Bangladesh Demographic and Health Surveys (DHS) with data on flooding derived from NASA Moderate Resolution Imaging Spectroradiometer (MODIS) satellites. Specifically, we compile birth records and other demographic data for women ages 15-49 years from the 2004, 2007, 2011, and 2014 DHS samples. Each of the DHS surveys in our sample includes a publicly available list of geocoordinates for DHS enumeration area centroids. We use these coordinates to link the DHS with administrative unit identifiers and corresponding subdistrict-level flooding measures (described below). The approximate locations of all DHS clusters in our sample and the corresponding sub-district boundaries are illustrated in Figure 1.

(Figure 1)

Our primary outcome of interest is fertility. We leverage the DHS birth records to construct a person-year dataset in which the outcome is a binary variable indicating whether woman $i$ had one or more children during year $t$. For each woman, the panel of observations begins in either the year 2004 - corresponding to year three of the flooding data — or the year they reached age 15, whichever occurs most recently. Women drop out of the sample at age 49 years or at the time of the survey, whichever comes first. We exclude non-permanent residents from the sample. After these restrictions, our analytic sample includes 335,532 person-year observations. The sample is described in Table 1. We apply DHS person weights to this and all subsequent analyses.

(Table 1)

Given that birth outcomes in a given time period reflect reproductive decisions and behaviors in prior months, our predictors of interest respectively capture flooding during the two 
years prior to the survey year. We measure flooding as follows. First, using 500m-resolution MODIS data, we calculate the Modified Normalized Difference Water Index (WNDWI, Chen et al. 2017; Chen \& Mueller 2018f; Xu 2006) for each grid cell in each subdistrict. We identify inundated cells as those with MNDWI values greater than 0.1. Second, for each year of interest, we find the maximum extent of a given subdistrict's area that was inundated during the monsoon season (July-December). Third, we distinguish flooding from standing water by subtracting the share of inundated cells observed during the dry season (January-March) from what was observed in the monsoon season. Finally, we standardize the observed maximum annual flooding extent over the flooding observed in all years in our dataset (2002-2014). Our final variables can therefore be interpreted as z-scores referenced against each sub-district's historical mean and standard deviation. Figure 2 provides an illustrative example of the geographic distribution of flooding (so defined) in the first year of MODIS data available (2002).

(Figure 2)

\section{Statistical Model}

We examine the relationship between flooding and fertility by estimating discrete-time eventhistory models where the outcome, childbearing in year $t$, is a function of the standardized measures of maximum flooding extent in years $t-1$ and $t-2$, a set of control variables, and both district and year fixed effects. We include as controls women's age, primary school attainment, parity (at start of year $t$ ), and residence in a rural or urban community. Period fixed effects flexibly capture changes that are common across each year in our dataset, and district fixed effects capture all time-invariant characteristics at the district level. Standard errors are clustered at the same subdistrict level that we measure flooding. 


\section{Analysis of Mechanisms}

We also conduct complementary analyses of the relationship between flood exposure and outcomes corresponding to some (but not all) of the mechanisms that may plausibly explain the relationship between flooding and fertility. We focus on four outcomes: marriage, contraceptive use, employment, and BMI. Since all four outcomes are measured at the time of the survey, this analysis proceeds using a pooled cross-sectional sample of the 2004, 2007, 2011, and 2014 DHS samples $(n=51,110)$. We model the first three outcomes as logits and the fourth outcome using a linear model. In all four models we include a comparable set of control variables (age, primary school attainment, parity, and rural (urban) residence) and fixed effects (district and year) as in the main analysis. We also include survey-month fixed effects to control for seasonality. Despite similar specifications of these models, the substantive differences between this pooled crosssectional dataset and the sample used for the main analyses of fertility require caution when drawing comparisons across models.

\section{Results}

\section{Main results}

We begin by estimating the overall relationship between flood exposure and the likelihood of subsequent childbearing. Since we have no strong a priori hypothesis about the degree to which the effects of flooding operate in a lagged manner, we proceed by modeling one- and two-year lags separately and then estimating a third model that includes both terms (Table 2). ${ }^{2}$ The results of the first model (Model 1) show that the probability of fertility in a given year is not influenced by flooding during the year immediately prior. However, in the second model (Model 2) we find

\footnotetext{
${ }^{2}$ The one- and two-year lagged terms are only weakly correlated $(r=-.0 .014)$.
} 
that fertility is negatively associated with flooding that occurred two years before $(\beta=-0.019)$. Each standard-deviation increase in flooding during year $t$ - 2 is associated with a 1.9 percent decrease in the odds of childbearing in year $t$. This result is not substantively affected by the addition of flooding during year $t-1$ as a control variable (Model 3), and inclusion of that control does not influence the coefficient estimate of interest in a meaningful manner.

(Table 2)

To further illustrate the relationship between flood exposure and fertility, we use the results from Model 3 to plot the predicted annual probability of fertility across a range of standardized flood values for year $t$-2, holding all other variables at their means (Figure 3). The results reveal a modest reduction in the probability of childbearing as the extent of flooding increases. For example, a woman exposed to flooding of $\mathrm{z}=2$ during year $t-2$ had a childbearing probability just under 0.075 , compared with a predicted probability of approximately 0.078 for a comparable woman exposed to the average historical flooding in her sub-district $(\mathrm{z}=0)$.

(Figure 3)

We next test for heterogeneity in flooding effects across select sub-populations (Table 3). First, we examine whether the effects of flooding vary by educational attainment. We distinguish between women who did and did not complete primary school-a schooling level exogenous to the flooding captured in our models (Model 4). ${ }^{3}$ We find a statistically significant difference in the association between flooding in year $t-2$ and fertility between these groups (interaction $\beta=-0.040$ ). The net effect of flooding in year $t$-2 on fertility is not statistically significant for women with less than a primary school education $(\beta=-0.002)$, but such flooding reduces fertility for women who

\footnotetext{
${ }^{3}$ Primary school attainment is typically determined prior to age 15 when women may enter our dataset, as well as age 13 when flooding exposure at year $t-2$ may be captured. This variable is therefore unlikely to be influenced by the flooding captured in our model.
} 
completed primary school (net $\beta=-0.029, \mathrm{OR}=0.971, \mathrm{p}=0.002$ ). For neither group does flooding during year $t-1$ influence fertility.

(Table 3)

Next, we test for interactions between flood exposure and parity, defined as the number of children born to a woman at the start of year $t$ (Model 5). Our results show a statistically significant and positive interaction between parity and flooding in year $t$-2 (interaction $\beta=0.022$ ). The estimates point to a scenario in which women with no or few children experience reductions in fertility due to flooding while higher-parity women experience flood-induced increases in the probability of childbearing. We illustrate these results (from Model 5) by plotting the marginal effects of flood exposure during year $t-2$ across a range of parities while holding other variables at their means (Figure 4). This figure shows a negative and statistically significant effect among childless women, which moderates and becomes non-significant among women with two children. As parities increase to four children and beyond, the effects of flooding become statistically significant and positive. The implication is that the sub-population of women who have had many children experiences and responds to the effects of flooding in a qualitatively different manner than the rest of the population. Again, we find no statistically significant associations between flooding during year $t-1$ and fertility, or interactions therein, in this model.

Our final interaction model (Model 6) tests for rural-urban differences in the relationship between flooding and fertility. ${ }^{4}$ The results indicate no statistically significant differences in the coefficients on the two flooding variables of interest.

(Figure 4)

\footnotetext{
${ }^{4}$ Rurality is defined according to the office definition that was current at the time of the DHS survey.
} 


\section{Robustness checks}

We test the sensitivity of our findings to three alternative measurement and modeling approaches (results in appendix Tables A1 and A2). First, we test for non-linearities in the association between flooding and fertility by including quadratic terms for flooding in years $t-1$ and $t-2$, respectively (Model A1). We find no evidence of such non-linearities, supporting our decision to retain only the linear terms in our main specifications. Second, we find the average standardized flood extent in years $t-1$ and $t-2$ and use this mean as the main predictor of interest in the regression model (Model A2). The coefficient on this variable is not statistically significant, which adds further evidence that flood effects operate with a two-year lag.

Third, we replace our standardized measures of flood extent with unstandardized indicators of area flooded (as defined above; see Figure A1 for example) and apply area fixed effects at the sub-district rather than district level (Model A3). This approach results in the exclusion of 254 observations from 9 sub-districts that lack variation in fertility outcomes, but yields results that are consistent with our main specification. Flooding in year $t-1$ is not a significant predictor of subsequent fertility, but flooding in year $t-2$ is associated with significant reductions in fertility during the year of observation. Here, it is important to note that the flood variables are constructed in terms of the maximum proportion of the sub-district that was inundated. The coefficients therefore represent the change in the log-odds of fertility that would occur as a sub-district shifts from 0 to 100 percent inundation. As such, plausible flood effects are likely to fall well within the 18.8 percent reduction in fertility odds implied by the coefficient estimate. 


\section{Mechanisms}

Our final set of analyses respectively examine the relationship between flooding and four outcomes corresponding to hypothesized causal mechanisms. Given the data available (see above), we conduct these analyses using a pooled cross-sectional dataset that is not strictly comparable to the analysis reported above. ${ }^{5}$ We begin by estimating logistic regression models of women's marital status (Model 7), contraceptive use (Model 8), and employment (Model 9), all measured at the time of the DHS interview (Table 4). We find no statistically significant associations between flood exposure and any of these outcomes, and this is true of flooding measured at both one- and two-year lags. We analyze the fourth outcome - women's BMI-using a linear model (Model 10, Table 5), which shows a non-significant association between flooding and this hypothesized pathway as well. As such, our results provide preliminary evidence that hypothesized marriage, contraceptive, employment, and health mechanisms are not supported. However, we underline our inability to draw direct comparisons across our analyses and acknowledge that other plausible pathways remain unexamined here.

(Table 4)

(Table 5)

\section{Discussion and Conclusion}

Our analysis of flooding and fertility in Bangladesh provides new evidence of the multiple ways in which households may modify their size and structure in response to environmental changes. While previous studies have documented the effects of flooding on migration (Gray \& Mueller 2012; Call et al. 2017), our findings suggest that households may also seek to modify (or control)

\footnotetext{
${ }^{5}$ Note that we have included a comparable pooled cross-sectional model of fertility in the 12 months prior to each survey in the appendix (Model A4, Table A2), which suggests non-significant flooding effects.
} 
household size and composition in situ by changing fertility behaviors. Alternatively, household members may engage in activities (e.g., migration) or experience changes (e.g., in health) that influence fertility indirectly, outside of intentional decision-making processes regarding the timing and number of births.

Overall, our findings suggest that flood exposure tends to reduce fertility and that these effects operate in a lagged manner. The probability of fertility in a given year is not statistically associated with the degree of flooding in the prior year but is influenced by the degree of flooding two years prior. Each standard-deviation increase in flooding during the monsoon season in year $t-2$ is associated with an approximately 2 percent decrease in the odds of childbearing in year $t$. This association is robust to multiple alternative specifications but remains relatively small in magnitude. However, when applied across a large population that is sometimes exposed to floods on the order of $z>2$, our findings suggest that flooding may result in an absolutely large number of births being delayed or forgone.

In addition to these overall estimates, we found that flooding effects on fertility varied across select sub-populations. Flooding reduced fertility among women with a primary school education or higher but was not significantly associated with changes in fertility among those with less education. One plausible explanation of this finding is that better-educated women may have greater access to the contraceptives needed to reduce fertility than less-educated women. Alternatively, better-educated women may be differentially positioned in the labor market and thus subject to different flood-induced economic changes than other women.

We also found evidence that the demographic impacts of flooding varied by parity. Flooding reduced fertility among women with zero or one children, but this effect was moderated and offset at higher parities. Indeed, women with four or more children experienced flood-induced 
increases in the likelihood of childbearing. It is important to note, however, that relatively few women in the sample had such high parities: the median parity (among person-year observations) was 2 , and just 10 percent of person-year observations had parities of 5 or higher. The implication is that high-parity women represent a unique — and likely uniquely disadvantaged — subpopulation in this context. Additional attention to this group and their anomalous reproductive responses to flooding is merited.

Our preliminary investigation into the causal mechanisms underlying the relationship between flooding and fertility provided little evidence to explain the observed flooding-fertility relationships we observe. Comparisons across these analyses are limited by differences in the data and methodology that were employed, and further analysis is needed. At least two additional steps can improve the study of causal mechanisms. First, analysis of these mechanisms should be conducted among the sub-populations for which we observe strong flooding effects on fertility, namely women who completed primary school and women at the low and high ends of the parity distribution. Second, the quasi-longitudinal components of the DHS (e.g., birth records, retrospective questions) should be further exploited to model as many mechanisms as possible in a longitudinal context comparable to the main models of fertility. At the very least, first marriage and child mortality can be modeled to assess the hypothesized marriage and replacement effect pathways. Given the considerable volume of data collected in Bangladesh, it may also be possible to draw on other sources of data to conduct parallel studies of other expected mechanisms.

In further analysis, we also plan to draw more direct links between our findings—-which focused on responses to previous flood events - and the increase in flooding that is expected to occur under future climate change scenarios. Such simulations will provide researchers and policymakers a new benchmark for understanding the interaction between flooding and population 
dynamics in Bangladesh. Finally, future research should work to examine the relationship between climatic variability (and correlated forms of environmental change) and fertility. Given the current dearth of evidence on this topic (Grace 2017), empirical findings from a range of contexts will allow researchers and other stakeholders to better understand and predict when, how, and why climate may influence fertility rates. 


\section{References}

Auerbach, L. W., Goodbred Jr, S. L., Mondal, D. R., Wilson, C. A., Ahmed, K. R., Roy, K., ... \& Ackerly, B. A. (2015). Flood risk of natural and embanked landscapes on the GangesBrahmaputra tidal delta plain. Nature Climate Change, 5(2), 153.

Bailey, R. C., Jenike, M. R., Ellison, P. T., Bentley, G. R., Harrigan, A. M., \& Peacock, N. R. (1992). The ecology of birth seasonality among agriculturalists in central Africa. Journal of Biosocial Science, 24(3), 393-412.

Banerjee, L. (2007). Effect of flood on agricultural wages in Bangladesh: An empirical analysis. World Development, 35(11), 1989-2009.

Barreca, A., Deschenes, O., \& Guldi, M. (2018). Maybe next month? Temperature shocks and dynamic adjustments in birth rates. Demography, 55(4), 1269-1293.

Behrman, J. A., \& Weitzman, A. (2016). Effects of the 2010 Haiti earthquake on women's reproductive health. Studies in Family Planning, 47(1), 3-17.

Bhuiyan, M. J. A. N., \& Dutta, D. (2012). Analysis of flood vulnerability and assessment of the impacts in coastal zones of Bangladesh due to potential sea-level rise. Natural Hazards, 61(2), 729-743.

Bilsborrow, R. E. (1987). Population pressures and agricultural development in developing countries: A conceptual framework and recent evidence. World Development, 15(2), 183203.

Bongaarts, J. (1980). Does malnutrition affect fecundity? A summary of evidence. Science, 208(4444), 564-569.

Borderon, M., Sakdapolrak, P., Muttarak, R., Kebede, E., Pagogna, R., \& Sporer, E. (2019). Migration influenced by environmental change in Africa: A systematic review of empirical evidence. Demographic Research, 41(18), 491-544.

Buller, A. M. B., Ranganathan, M., Bleile, A., Hidrobo, M., \& Heise, L. (2018). A mixedmethod review of cash transfers and intimate partner violence in low and middle-income countries. The World Bank Research Observer.

Burlando, A. (2014). Power outages, power externalities, and baby booms. Demography, 51(4), 1477-1500.

Call, M. A., Gray, C., Yunus, M., \& Emch, M. (2017). Disruption, not displacement: environmental variability and temporary migration in Bangladesh. Global Environmental Change, 46, 157-165.

Carleton, T. A., \& Hsiang, S. M. (2016). Social and economic impacts of climate. Science, 353(6304), aad9837.

Chen, J., \& Mueller, V. (2018, forthcoming). Salt of the earth: Migration, adaptation, and soil salinity in coastal Bangladesh. Nature Climate Change.

Chen, J. J., Mueller, V., Jia, Y., \& Tseng, S. K. H. (2017). Validating migration responses to flooding using satellite and vital registration data. American Economic Review, 107(5), 441-45.

Davis, K. (1963). The theory of change and response in modern demographic history. Population Index, 29(4), 345-366.

Deschênes, O., \& Greenstone, M. (2011). Climate change, mortality, and adaptation: Evidence from annual fluctuations in weather in the US. American Economic Journal: Applied Economics, 3(4), 152-85.

De Sherbinin, A., VanWey, L. K., McSweeney, K., Aggarwal, R., Barbieri, A., Henry, S., ... \& 
Walker, R. (2008). Rural household demographics, livelihoods and the environment. Global Environmental Change, 18(1), 38-53.

Douglas, I. (2009). Climate change, flooding and food security in south Asia. Food Security, $1(2), 127-136$.

Eastwood, R., \& Lipton, M. (1999). The impact of changes in human fertility on poverty. The Journal of Development Studies, 36(1), 1-30.

Eissler, S., Thiede, B. C., \& Strube, J. (2019). Climatic variability and changing reproductive goals in Sub-Saharan Africa. Global Environmental Change, 57, in press.

Eloundou-Enyegue, P. M., \& Williams, L. B. (2006). Family size and schooling in sub-Saharan African settings: a reexamination. Demography, 43(1), 25-52.

Fussell, E., Hunter, L. M., \& Gray, C. L. (2014). Measuring the environmental dimensions of human migration: The demographer's toolkit. Global Environmental Change, 28, 182191.

Grace, K. (2017). Considering climate in studies of fertility and reproductive health in poor countries. Nature Climate Change, 7(7), 479.

Grace, K., Davenport, F., Hanson, H., Funk, C., \& Shukla, S. (2015). Linking climate change and health outcomes: examining the relationship between temperature, precipitation and birth weight in Africa. Global Environmental Change, 35, 125-137.

Gray, C. L., \& Mueller, V. (2012). Natural disasters and population mobility in Bangladesh. Proceedings of the National Academy of Sciences, 201115944.

Heuveline, P., \& Poch, B. (2007). The Phoenix population: Demographic crisis and rebound in Cambodia. Demography, 44(2), 405-426.

Hidrobo, M., Peterman, A., \& Heise, L. (2016). The effect of cash, vouchers, and food transfers on intimate partner violence: evidence from a randomized experiment in Northern Ecuador. American Economic Journal: Applied Economics, 8(3), 284-303.

Hunter, L. M., Luna, J. K., \& Norton, R. M. (2015). Environmental dimensions of migration. Annual Review of Sociology, 41, 377-397.

Islam, M. N., \& Uyeda, H. (2007). Use of TRMM in determining the climatic characteristics of rainfall over Bangladesh. Remote Sensing of Environment, 108(3), 264-276.

Kalipeni, E. (1996). Demographic response to environmental pressure in Malawi. Population and Environment, 17(4), 285-308.

Larsen, A. F., Headey, D., \& Masters, W. A. (2019). Misreporting month of birth: Diagnosis and implications for research on nutrition and early childhood in developing countries. Demography, 56(2), 707-728.

McMichael, A. J., Woodruff, R. E., \& Hales, S. (2006). Climate change and human health: present and future risks. The Lancet, 367(9513), 859-869.

Mirza, M. M. Q. (2011). Climate change, flooding in South Asia and implications. Regional Environmental Change, 11(1), 95-107.

Mobarak, A. M., Kuhn, R., \& Peters, C. (2013). Consanguinity and other marriage market effects of a wealth shock in Bangladesh. Demography, 50(5), 1845-1871.

Nobles, J., Frankenberg, E., \& Thomas, D. (2015). The effects of mortality on fertility: population dynamics after a natural disaster. Demography, 52(1), 15-38.

Sellers, S., \& Gray, C. (2019). Climate shocks constrain human fertility in Indonesia. World Development, 117, 357-369.

Simon, D. H. (2017). Exploring the influence of precipitation on fertility timing in rural Mexico. Population and Environment, 38(4), 407-423. 
Udry, J. R. (1970). The effect of the great blackout of 1965 on births in New York City. Demography, 7(3), 325-327.

$\mathrm{Xu}, \mathrm{H}$. (2006). Modification of Normalised Difference Water Index (NDWI) to enhance open water features in remotely sensed imagery." International Journal of Remote Sensing, 27 (14), 3025-33. 


\section{Tables}

Table 1 Summary of variables

\begin{tabular}{lcccc}
\hline Variable & Mean & SD & Min & Max \\
\hline Birth = yes & 0.099 & - & 0 & 1 \\
Flooding (z-score), t-1 & 0.026 & 0.957 & -2.555 & 3.189 \\
Flooding (z-score), t-2 & 0.113 & 0.982 & -2.555 & 3.189 \\
Age (years) & 28.715 & 8.732 & 15 & 49 \\
Primary school = yes & 0.694 & - & 0 & 1 \\
Parity & 2.407 & 1.919 & 0 & 20 \\
Rural = yes & 0.730 & - & 0 & 1 \\
Year & 2008 & - & 2004 & 2014 \\
$\quad$ N (person-years) & \multicolumn{3}{c}{335,786} \\
\hline Person weights applied in all analyses.
\end{tabular}


Table 2 Logistic regression models predicting the birth of $1+$ child in year $t$

\begin{tabular}{|c|c|c|c|c|c|c|c|c|c|c|c|c|}
\hline & \multicolumn{4}{|c|}{ Model 1} & \multicolumn{4}{|c|}{ Model 2} & \multicolumn{4}{|c|}{ Model 3} \\
\hline & $\beta$ & & OR & SE & $\beta$ & & OR & SE & $\beta$ & & OR & SE \\
\hline Flooding (z-score), t-1 & 0.011 & & 1.011 & 0.009 & & & & & 0.010 & & 1.010 & 0.009 \\
\hline Flooding (z-score), t-2 & & & & & -0.019 & $* *$ & 0.981 & 0.008 & -0.019 & ** & 0.981 & 0.008 \\
\hline Age (years) & -0.070 & $* \star \star$ & 0.932 & 0.003 & -0.070 & *** & 0.932 & 0.003 & -0.070 & $* * *$ & 0.932 & 0.003 \\
\hline Primary school = yes & -0.179 & $* * *$ & 0.836 & 0.021 & -0.179 & $* * *$ & 0.836 & 0.021 & -0.179 & $* * *$ & 0.836 & 0.021 \\
\hline Parity & -0.144 & *** & 0.866 & 0.016 & -0.144 & $* * *$ & 0.866 & 0.016 & -0.144 & $* * *$ & 0.866 & 0.016 \\
\hline Rural $=$ yes & 0.174 & $* * *$ & 1.190 & 0.024 & 0.174 & $* * *$ & 1.190 & 0.024 & 0.174 & $* * *$ & 1.190 & 0.024 \\
\hline District fixed effects & \multicolumn{4}{|c|}{ Yes } & \multicolumn{4}{|c|}{ Yes } & \multicolumn{4}{|c|}{ Yes } \\
\hline Year fixed effects & \multicolumn{4}{|c|}{ Yes } & \multicolumn{4}{|c|}{ Yes } & \multicolumn{4}{|c|}{ Yes } \\
\hline $\mathrm{N}$ (person-years) & \multicolumn{4}{|c|}{335,786} & \multicolumn{4}{|c|}{335,786} & \multicolumn{4}{|c|}{335,786} \\
\hline
\end{tabular}


Table 3 Logistic regression models predicting the birth of $1+$ child in year $t$, with interactions

\begin{tabular}{|c|c|c|c|c|c|c|c|c|c|c|c|c|}
\hline & \multicolumn{4}{|c|}{ Model 4} & \multicolumn{4}{|c|}{ Model 5} & \multicolumn{4}{|c|}{ Model 6} \\
\hline & $\beta$ & & OR & SE & $\beta$ & & OR & SE & $\beta$ & & OR & SE \\
\hline Flooding (z-score), t-1 & -0.002 & & 0.998 & 0.016 & -0.006 & & 0.994 & 0.014 & 0.018 & & 1.018 & 0.016 \\
\hline Flooding (z-score), t-2 & 0.011 & & 1.011 & 0.015 & -0.054 & *** & 0.947 & 0.014 & -0.038 & ** & 0.963 & 0.018 \\
\hline Flooding ( $\mathrm{z}$-score), $\mathrm{t}-1$ * primary school $=$ yes & 0.016 & & 1.016 & 0.018 & & & & & & & & \\
\hline Flooding ( $\mathrm{z}$-score), $\mathrm{t}-2{ }^{*}$ primary school $=$ yes & -0.040 & ** & 0.961 & 0.017 & & & & & & & & \\
\hline Flooding (z-score), t-1 * parity & & & & & 0.011 & & 1.011 & 0.007 & & & & \\
\hline Flooding (z-score), t-2 * parity & & & & & 0.022 & ** & 1.023 & 0.006 & & & & \\
\hline Flooding ( $\mathrm{z}$-score), $\mathrm{t}-1$ * rural $=$ yes & & & & & & & & & -0.010 & & 0.990 & 0.018 \\
\hline Flooding ( $\mathrm{z}$-score), $\mathrm{t}-2$ * rural $=$ yes & & & & & & & & & 0.025 & & 1.025 & 0.020 \\
\hline Age (years) & -0.070 & $* * *$ & 0.932 & 0.003 & -0.070 & *** & 0.932 & 0.003 & -0.070 & 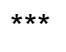 & 0.932 & 0.003 \\
\hline Primary school $=$ yes & -0.174 & $* * *$ & 0.840 & 0.022 & -0.178 & *** & 0.837 & 0.021 & -0.179 & *** & 0.836 & 0.021 \\
\hline Parity & -0.144 & $* * *$ & 0.866 & 0.016 & -0.149 & *** & 0.862 & 0.017 & -0.144 & *** & 0.866 & 0.016 \\
\hline Rural $=$ yes & 0.174 & $* * *$ & 1.190 & 0.024 & 0.175 & *** & 1.191 & 0.024 & 0.172 & *** & 1.188 & 0.024 \\
\hline District fixed effects & & & Yes & & & & es & & & & es & \\
\hline Year fixed effects & & & Yes & & & & es & & & & es & \\
\hline $\mathrm{N}$ (person-years) & & & 5,786 & & & & 5,786 & & & & 786 & \\
\hline
\end{tabular}


Table 4 Logistic regression models predicting marital status, contraceptive use, and employment

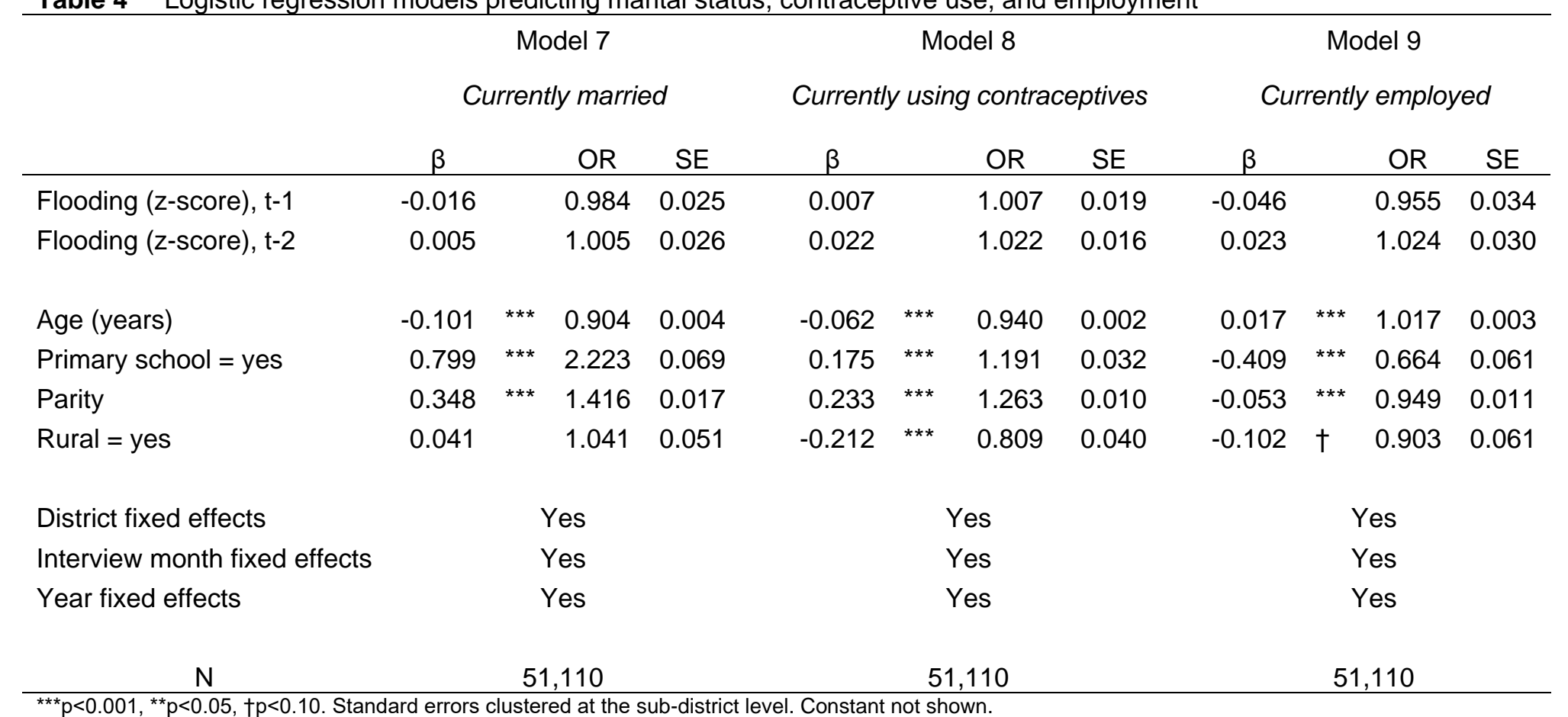


Table 5 Linear regression models predicting Body Mass Index (BMI)

\begin{tabular}{|c|c|c|c|}
\hline & \multicolumn{3}{|c|}{$\begin{array}{c}\text { Model } 10 \\
\text { BMI }\end{array}$} \\
\hline & $\beta$ & & SE \\
\hline Flooding (z-score), t-1 & 2.008 & & 3.065 \\
\hline Flooding (z-score), t-2 & -3.602 & & 2.767 \\
\hline Age (years) & 9.746 & $* * *$ & 0.833 \\
\hline Primary school $=$ yes & 129.833 & $* * *$ & 8.172 \\
\hline Parity & -22.759 & $* * *$ & 1.850 \\
\hline Rural $=$ yes & 130.782 & 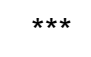 & 9.255 \\
\hline District fixed effects & & Yes & \\
\hline Interview months fixed effects & & Yes & \\
\hline Year fixed effects & & Yes & \\
\hline $\mathrm{N}$ & 5 & 0,361 & \\
\hline
\end{tabular}




\section{Figures}

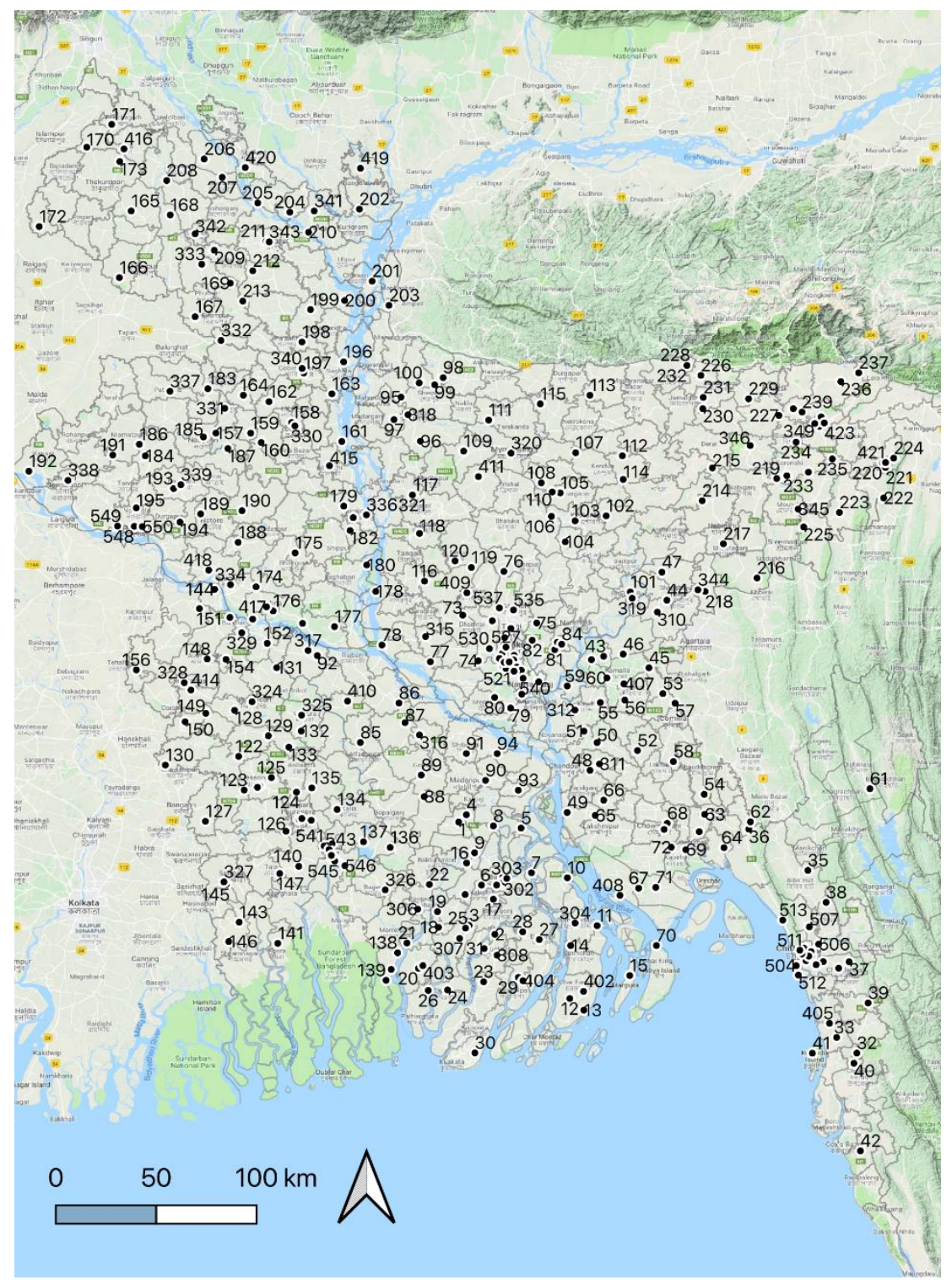

Figure 1 Map of approximate DHS cluster locations and sub-district boundaries 


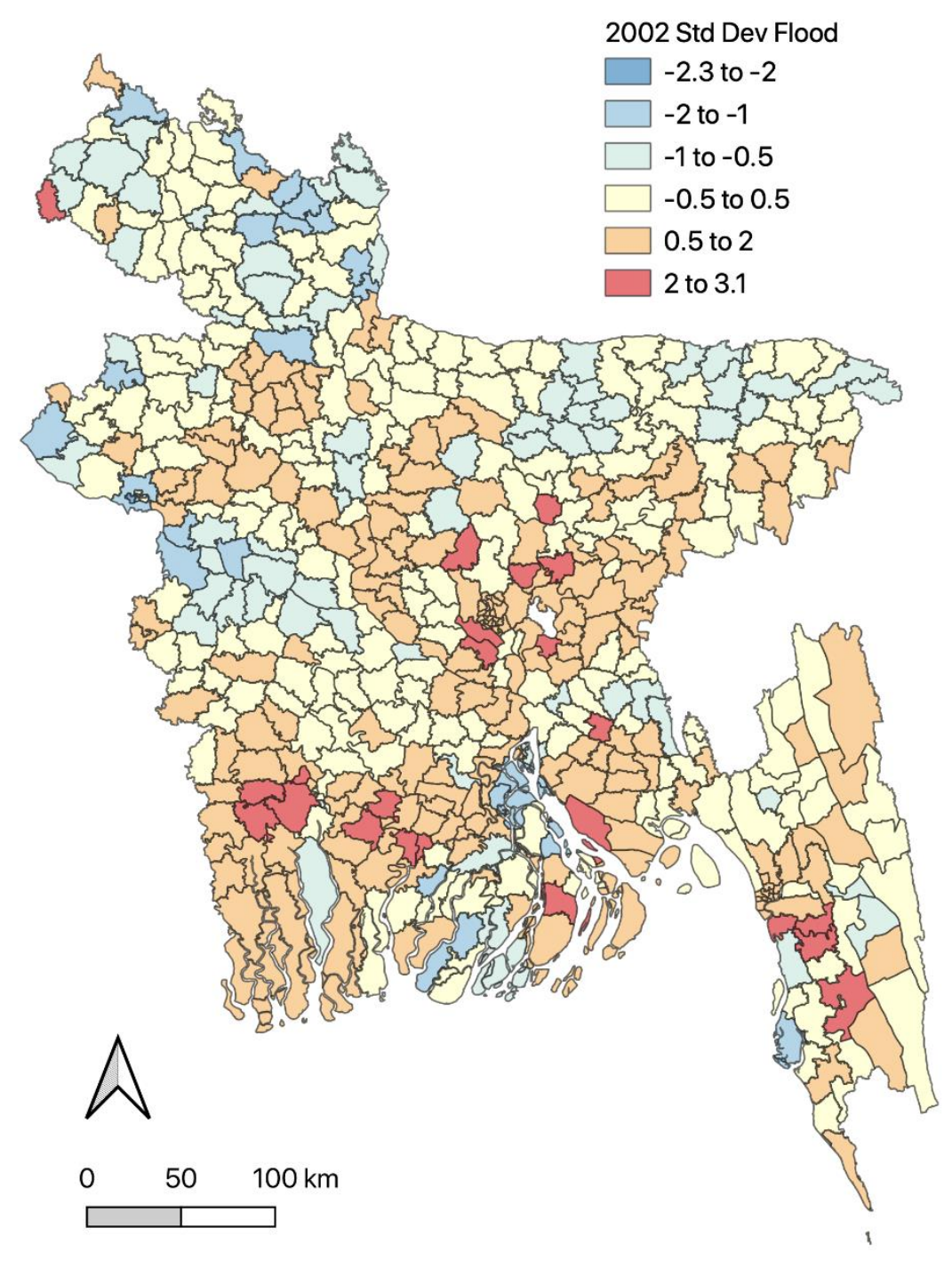

Figure 2 Map of sub-district flooding (standardized), 2002 


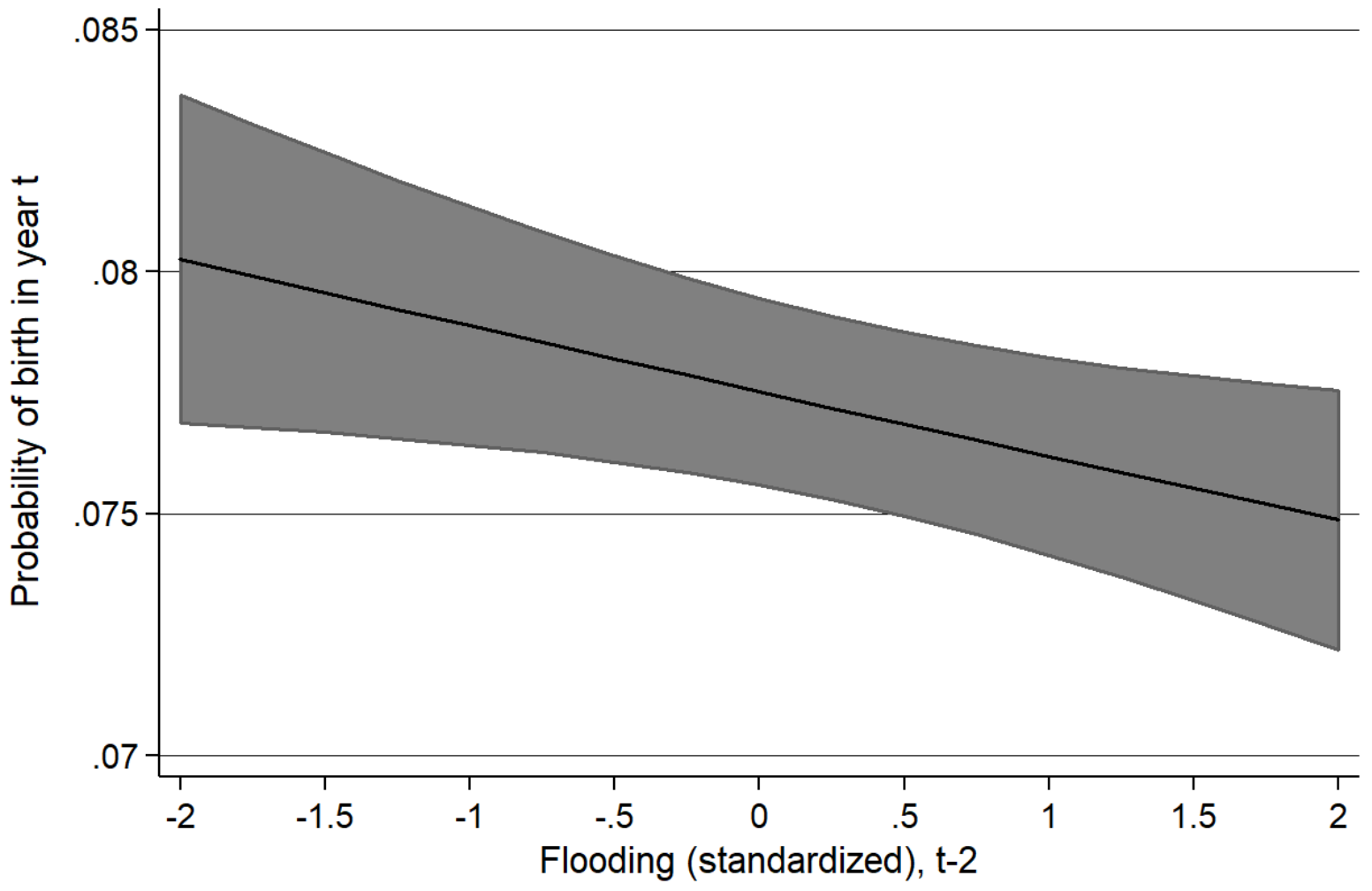

Figure 3 Predicted probability of $1+$ birth in year t, by flooding (standardized) in year t-2 


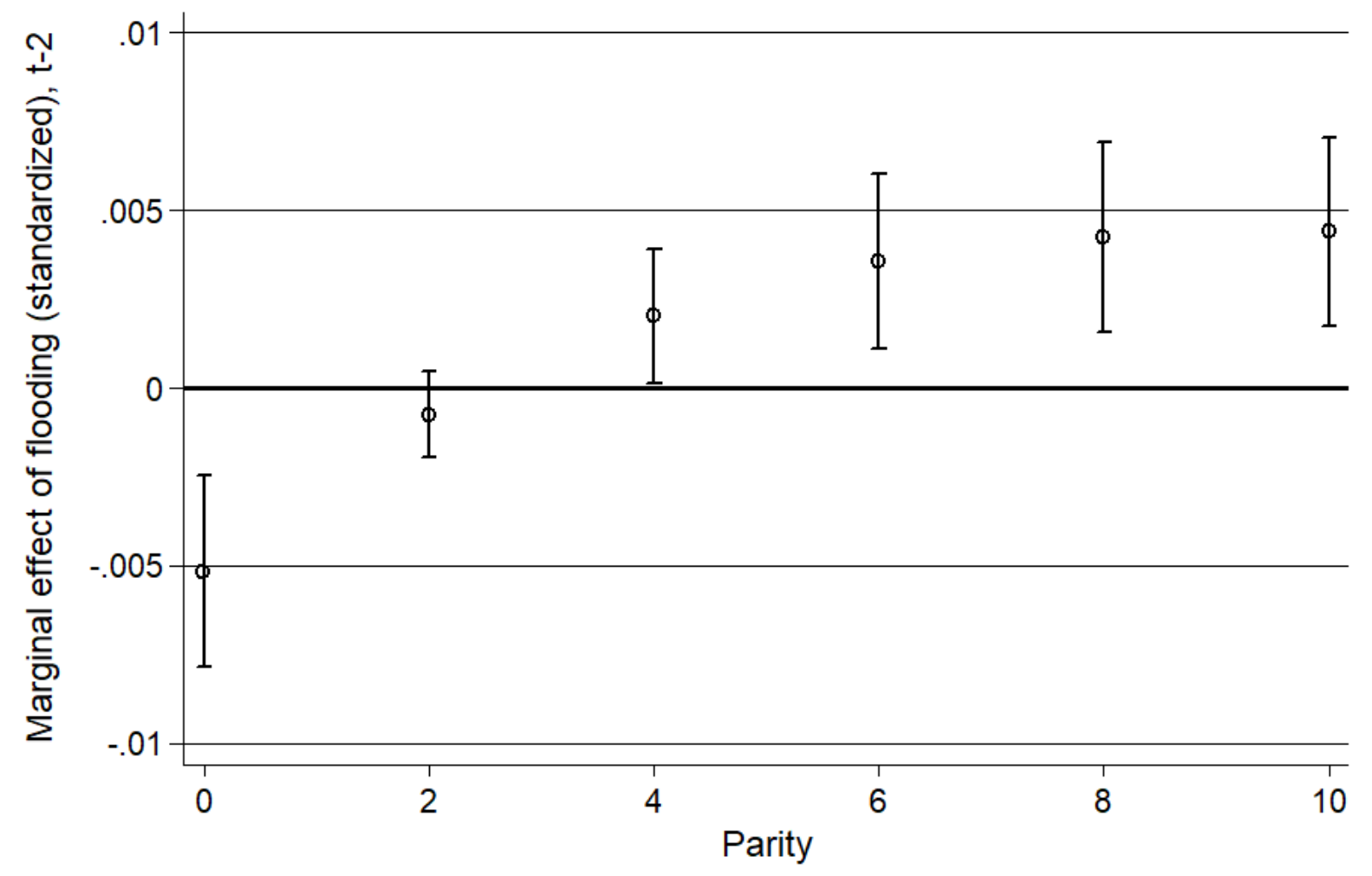

Figure 4 Marginal effect of flooding (standardized) in year $t-2$ on the likelihood of $1+$ birth in year t, by parity 


\section{Appendix}

Table A1 Logistic regression models predicting the birth of $1+$ child in year $t$

\begin{tabular}{|c|c|c|c|c|c|c|}
\hline & \multicolumn{3}{|c|}{ Model A1 } & \multicolumn{3}{|c|}{ Model A2 } \\
\hline & $\beta$ & OR & SE & $\beta$ & OR & SE \\
\hline Flooding (z-score), t-1 & 0.007 & 1.007 & 0.011 & & & \\
\hline Flooding (z-score) $)^{2}, \mathrm{t}-1$ & 0.004 & 1.004 & 0.007 & & & \\
\hline Flooding (z-score), t-2 & -0.022 & ** 0.978 & 0.010 & & & \\
\hline Flooding (z-score) $)^{2}, \mathrm{t}-2$ & 0.003 & 1.003 & 0.006 & & & \\
\hline Flooding (z-score), mean of $\mathrm{t}-1, \mathrm{t}-2$ & & & & -0.009 & 0.991 & 0.012 \\
\hline \multicolumn{7}{|l|}{ Flooding (\%), t-1 } \\
\hline \multicolumn{7}{|l|}{ Flooding (\%), t-2 } \\
\hline Age (years) & -0.070 & 0.932 & 0.003 & -0.070 & $* * * \quad 0.932$ & 0.003 \\
\hline Primary school $=$ yes & -0.179 & 0.836 & 0.021 & -0.179 & $* * * \quad 0.836$ & 0.021 \\
\hline Parity & -0.144 & 0.866 & 0.016 & -0.144 & $* * * \quad 0.866$ & 0.016 \\
\hline Rural $=$ yes & 0.174 & 1.190 & 0.024 & 0.174 & $* \star \star \quad 1.190$ & 0.024 \\
\hline Panel data & \multicolumn{3}{|c|}{ Yes } & \multicolumn{3}{|c|}{ Yes } \\
\hline Sub-district fixed effects & \multicolumn{3}{|c|}{ No } & \multicolumn{3}{|c|}{ No } \\
\hline District fixed effects & \multicolumn{3}{|c|}{ Yes } & \multicolumn{3}{|c|}{ Yes } \\
\hline Interview month fixed effects & \multicolumn{3}{|c|}{ No } & \multicolumn{3}{|c|}{ No } \\
\hline Year fixed effects & \multicolumn{3}{|c|}{ Yes } & \multicolumn{3}{|c|}{ Yes } \\
\hline $\mathrm{N}$ & \multicolumn{3}{|c|}{335,786} & \multicolumn{3}{|c|}{335,786} \\
\hline
\end{tabular}


Table A2 Logistic regression models predicting the birth of $1+$ child in year $t$

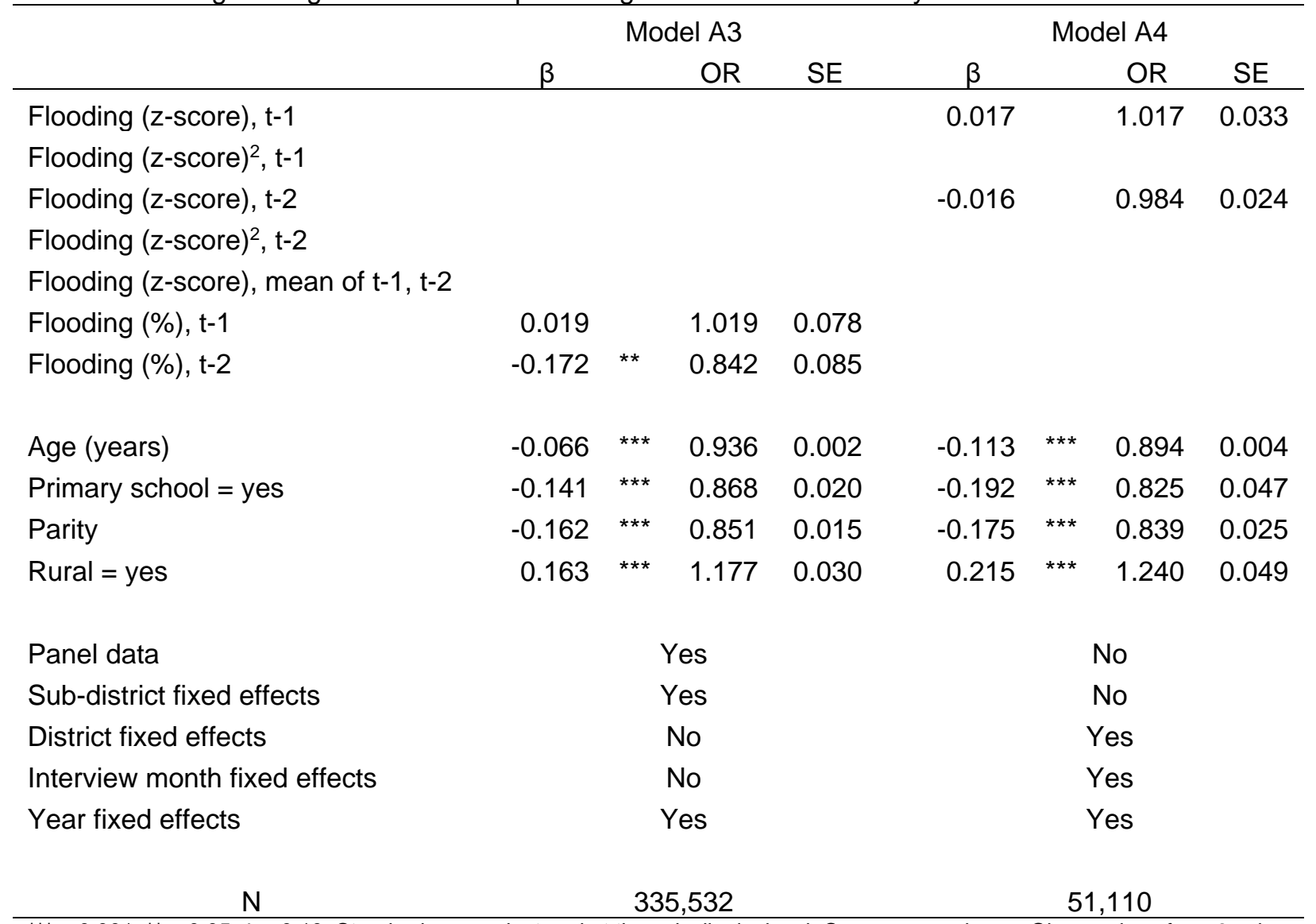

${ }^{* * *} p<0.001,{ }^{* *} p<0.05,+p<0.10$. Standard errors clustered at the sub-district level. Constant not shown. Observations from 9 subdistricts omitted from Model A3 due to lack of variation in outcome variable within sub-districts. 


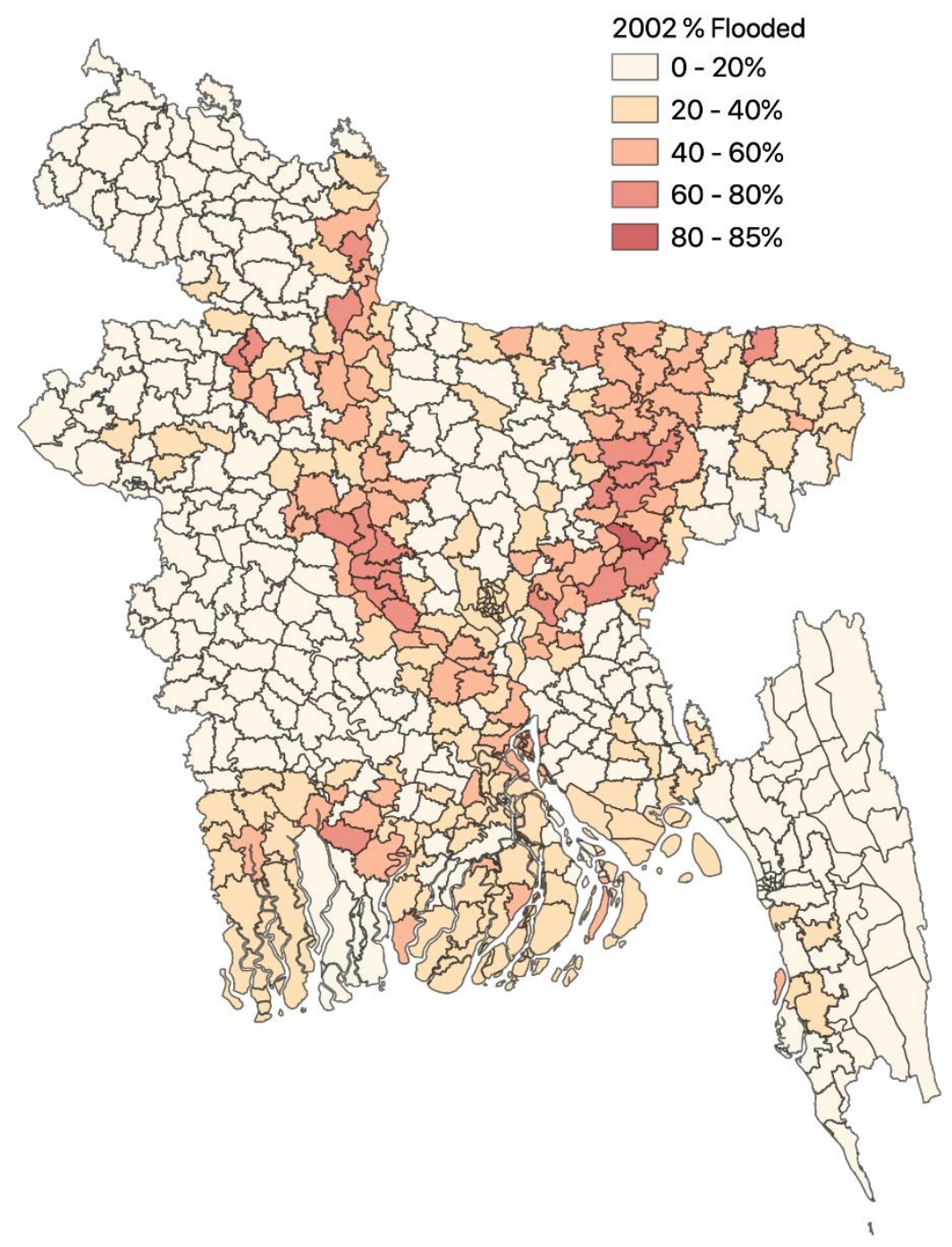

Figure A1 Map of sub-district flooding (unstandardized), 2002 